\title{
Cartografia Social da Comunidade Quilombola da Serra do Evaristo- Baturité - CE: Um estudo de caso
}

\author{
Community Social Cartography Quilombo Serra do Evaristo-Baturité - CE: A case study \\ Silva $^{1}$, A.B de O.; Lima $^{2}$, A. E.F.; Pereira ${ }^{3}$, G.; Sampaio ${ }^{4}$, J.L.F. \\ contatosbrenosbrenos@gmail.com
}

\section{Resumo}

Com base em metodologias cartográficas colaborativas, deu-se a construção do mapeamento da Comunidade Quilombola Serra do Evaristo. Tendo a cartografia social como objeto de análise, observa-se como o processo metodológico contribui para o fortalecimento e autoconhecimento das relações cotidianas da comunidade e seu território. Haja vista o intuito de explanar sobre como o mapeamento de suas simbologias, crenças e relações com a terra são também de interesse político, sobretudo em cenários conflituosos. Dessa forma, ocasionando a junção de potencialidades e pontos negativos, sob o olhar dos sujeitos sociais internos, assim possibilitando uma conclusão crítica para futuras melhorias. A cartografia social tem a finalidade de posicionar o mapeado como protagonista e a etnografia é o objeto para embasamento sobre identidade coletiva. A partir das informações obtidas anteriormente nas demarcações, as conclusões seguem pela relevância da construção desse mapeamento participativo para uma nova perspectiva sob valores próprios e singulares da comunidade.

Palavras-chave: Cartografia Social, Quilombo, Comunidades Tradicionais

\begin{abstract}
Based on collaborative cartographic methodologies, there was the construction of the mapping of the Community Quilombola Serra do Evaristo. Having social cartography as an object of analysis, we observe how the methodological process contributes to the strengthening and self-knowledge of the daily relationships of the community and its territory. In view in order to explain how the mapping of their symbols, beliefs and relationships with the land are also political interest, especially in conflictive scenarios. Thus, causing the junction strengths and weaknesses, under the gaze of internal social subjects, thus enabling a critical conclusion for future improvements. Social mapping is intended to position the mapped as protagonist and ethnography is the object to foundation of collective identity. From the information previously obtained in the demarcations, the conclusions follow the relevance of the construction of participatory mapping to a new perspective on themselves and singular values of the community.
\end{abstract}

Keywords: Social Cartography, Quilombo, Traditional communities

1Antonio Breno de O. Silva, Gastronomia/Núcleo de Estudos Afro-Brasileiro e Indígena (NEABI), IFCE, Baturité-CE, Brasil 2Anna Erika Ferreira Lima, Professora Dra. Do Curso de Gastronomia/Coordenadora do Núcleo de Estudos Afro-Brasileiro e Indígena (NEABI), IFCE, Baturité-CE, Brasil

3Gino Pereira, PRODEMA/Laboratório de Estudos Agrários e Territoriais (LEAT - UFC), UFC, Fortaleza-CE, Brasil.

4 José Levi Furtado Sampaio, Prof. Dr. PRODEMA/Laboratório de Estudos Agrários e Territoriais (LEAT - UFC), UFC, FortalezaCE, Brasil. 


\section{INTRODUÇÃO}

O mapeamento participativo de comunidades tradicionais permite a análise da dimensão territorial, cultural e de pertencimento. A Cartografia Social vem com esse intuito em suas práticas metodológicas e propõe à comunidade utilizar os mapas como agentes em possíveis cenários de conflito, promove o autoconhecimento e amplia a visão coletiva de suas crenças, espaços simbólicos, atividades de trabalho, alimentação e patrimônios de diversas naturezas. Esse modelo de cartografia tem o ponto de vista do próprio sujeito que contrasta com os elementos que serão mapeados no senso de identidade coletiva (GORAYEB, 2014).

O processo participativo quebra o mapeamento de dinâmica individual, porque permite que a relação dos sujeitos que ali vivem sejam expandidas documentalmente para instrumento de defesa, preservação e pertencimento. Abordando experiências cotidianas, suas relações com a terra e simbologias culturais da comunidade se estabelecem uma visão horizontal diferente de hierarquias típicas de outras culturas. Ou seja, o posicionamento das pessoas perante o mapeamento executa-se de maneira linear em que todos os sujeitos têm voz e podem compartilhar de suas vivências (GORAYEB; MEIRELES, 2014).

A pesquisa e acompanhamento da representação do território da Comunidade Quilombola da Serra do Evaristo - Baturité - CE foi uma parceria do Núcleo de Estudos Afro Brasileiros e Indígenas do Instituto Federal de Educação, Ciência e Tecnologia - Campus Baturité (NEABI/IFCE) juntamente com o Laboratório de Geoprocessamento da Universidade Federal do Ceará (Labocart/ UFC).

O mapeamento deu-se em um momento no qual a bananicultura vem tomando dimensões que não são habituais na vivência histórica da comunidade, estabelecendo assim um cenário de conflito, tendo também outra problemática vinculada a vendas de propriedades da mencionada comunidade que está localizada a $6 \mathrm{~km}$ do centro da cidade de Baturité, possui 150 famílias e 564 habitantes, tendo uma divisão interna de famílias sendo estas: Bentos, Soares, Venâncios, Juliões e Leandros. Uma vez que essa característica de identificação pode tornar plural os significados individuais sobre o espaço que vivem, embora o coletivo permaneça na busca por autonomia. $\mathrm{O}$ acesso ao quilombo se dá por estradas vicinais, passando por trechos sinuosos, tendo em vista que a comunidade é o último ponto que esta nos leva. As dificuldades rodeiam saúde e educação, sendo que não possuem posto de saúde e apenas escola de nível básico, o que causa evasão dos moradores mais jovens.

Portanto, traçamos por objetivo geral elaborar a cartografia social do Quilombo da Serra do Evaristo - Baturité - CE, por meio da construção de mapeamentos temáticos, utilizando-se como 
base a transferência de tecnologias e a participação ativa da população local. Assim representar cartograficamente os territórios rurais do quilombo, atentando para elementos e aspectos relevantes da comunidade, utilizando-se ferramentas das geotecnologias open-source. E principalmente dar maior visibilidade à comunidade no meio acadêmico, para que assim, tenhamos uma descrição de seus problemas e possíveis soluções.

A construção da cartografia participativa trata de questões amplas e coletivas que por vezes se encontram em vulnerabilidade, promovida a partir de interesses individuais externos. Não é a construção de uma narrativa que objetiva isolar esses sujeitos, mas sim de empoderá-los através de suas rotas diárias partindo de uma organização geográfica de perspectiva mais interna e menos de interferência técnica absoluta.

\section{METODOLOGIA}

Iniciado em dezembro de 2014, o projeto supracitado foi proposto à comunidade em março de 2015 e com aprovação, deram-se início aos encontros. Para análise desse conjunto de ações tivemos revisão bibliográfica de Littler (2010) e Lakatos; Marconi (2010). Tendo também contribuição de gravações de áudio, relatórios e fotografias. Assim estabelecemos a metodologia externa à aplicada pela cartografia social, já que propomos um estudo de caso.

Sobre a metodologia cartográfica utilizada: 1) O processo metodológico participativo se inicia com o diálogo sobre como se constrói uma Cartografia, o que é Cartografia Social e como sua execução pode assegurar a comunidade em cenários específicos. 2) Após, o exercício de autoconhecimento se principia em indicar potencialidades e fraquezas específicas do quilombo. Além de simbologias próprias, como a Árvore do Fato, que trata-se de uma mangueira. Nesse momento é que se introduz o peculiar da cartografia social, nenhum outro sujeito externo poderia eleger esses elementos com tal propriedade. 3) Em sequência reuniu-se as observações e a prática de localizar tais coordenadas anteriormente citadas, adicionando pontos no mapa em foto de satélite como: escola, área de desmatamento, área com escassez de água, mulheres "rezadeiras", plantação de bananeira, casas. Juntamente com auxílio de materiais didáticos. 4) Monta-se um mapa para apresentação confirmatória da comunidade, para que ela verifique se a representação digital e legenda estão de acordo com as marcações. 5) É finalizada e entregue a cartografia participativa. Na figura 01, visualizamos o segundo encontro no desenvolvimento da Cartografia Social, onde todos se voltam para as análises internas 


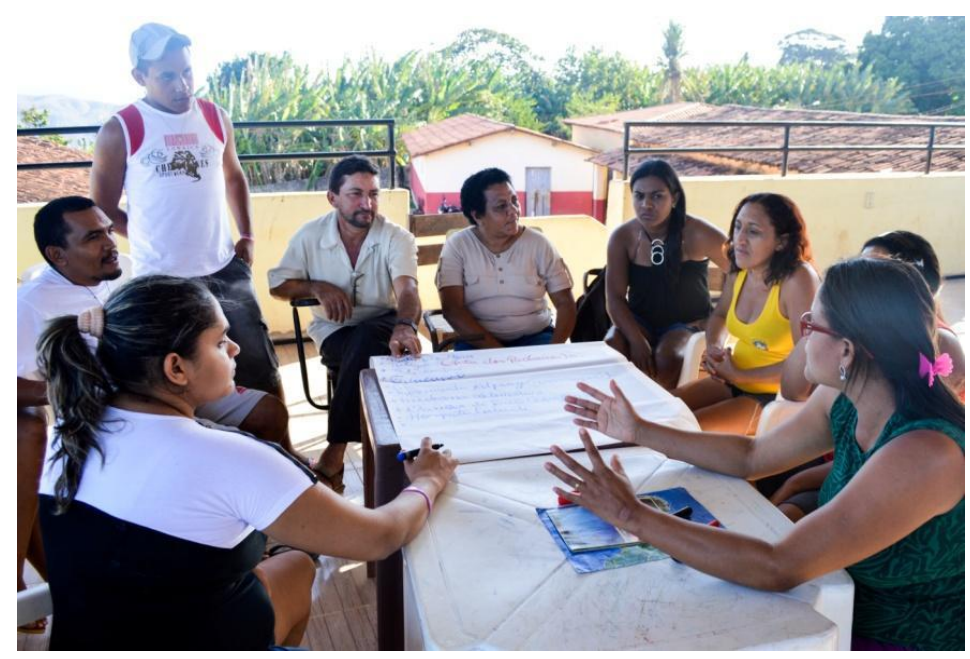

Figura 01: Segundo encontro com a Comunidade Quilombola da Serra do Evaristo.

Foto: Lima, 2015.

Considerando que além do procedimento técnico da Cartografia Social, também foi utilizada como metodologia a etnografia. A etnografia enquanto método é uma observação dos participantes e do espaço que está inserido. Tendo que designar o trabalho de campo no seu conjunto, desde a chegada ao campo da investigação, quando inicia as negociações que darão o ponto inicial, até ao momento de encerramento. Enquanto presentes, os observadores imergiram pessoalmente na vida dos locais, partilhando as suas experiências.

No caso da presente pesquisa, foram efetivados quarto trabalhos de campo, onde os mesmos referiram-se, ao Quadro 1 - Tema das oficinas com número de pessoas e grupos participantes.

\begin{tabular}{|c|c|c|}
\hline Oficina & Número de Pessoas & Grupos Participantes \\
\hline Assembléia de mobilização & 32 & $\begin{array}{l}\text { Mulheres, agricultores, jovens, professores e } \\
\text { troncos velhos. }\end{array}$ \\
\hline Diagnóstico Participativo & 35 & $\begin{array}{l}\text { Mulheres, agricultores, jovens, professores e } \\
\text { troncos velhos. }\end{array}$ \\
\hline $\begin{array}{l}\text { Apresentação e Discussão dos } \\
\text { Problemas }\end{array}$ & 32 & Mulheres, jovens, professores e troncos velhos. \\
\hline Mapeamento Propositivo & 38 & $\begin{array}{l}\text { Mulheres, crianças, agricultores, jovens, } \\
\text { professores e troncos velhos. }\end{array}$ \\
\hline
\end{tabular}




\begin{tabular}{|l|l|l|}
\hline Ajuste dos Mapas & 30 & $\begin{array}{l}\text { Mulheres, agricultores, jovens, professores e } \\
\text { troncos velhos. }\end{array}$ \\
\hline Entrega dos Mapas & 35 & $\begin{array}{l}\text { Mulheres, agricultores, crianças, jovens, } \\
\text { professores e troncos velhos. }\end{array}$ \\
\hline
\end{tabular}

Fonte: Pesquisa Direta, 2016.

a) A Assembléia de mobilização da comunidade para o desenvolvimento da pesquisa; b) Oficina de Diagnóstico Participativo, onde onde foram discutidos os problemas e potencialidades da comunidade, onde encaminhou-se os desdobramentos do projeto e a importância da cartografia social; c) $\mathrm{O}$ terceiro encontro foram debatidos os resultados do diagnóstico participativo; d) No quarto momento foram identificados os pontos a serem registrados no mapa pelos participantes do quilombo; o que a Comunidade decidiu de importante para ser mapeado; e) O quinto encontro referiu-se a apresentação da primeira versão do mapa com os pontos definidos pela comunidade, onde os mesmos efetivaram a correção dos pontos que não foram registrados corretamente; f) $\mathrm{O}$ quarto momento foi a entrega do Mapa final após as retificações.

Após os seis momentos indicados, foram entregues quatro mapas sociais desenvolvidos a partir das indicações da comunidade sobre o que era de interesse do grupo de mulheres, agricultores, jovens, professores e troncos velhos.

\section{DEBATENDO OS RESULTADOS: $O$ RESULTADO DA EXPERIÊNCIA DE CARTOGRAFIA SOCIAL}

É importante estabelecer a discussão que Tradicionalmente, a Cartografia foi sempre uma ferramenta monopolizada pelo Estado e organizações internacionais de controle (Banco Mundial, Organização Mundial do Comércio, Organização das Nações Unidas, etc.), utilizada como estratégia de dominação, afirmação de poder e controle social (LACOSTE, 1997). O mapa torna visível o que é interessante que se veja, e invisível o que não se quer mostrar, como afirma Oliveira et. al. (2010). Para o autor (op.cit), no entanto, como uma alternativa de representação territorial apoderada pelos Povos e Comunidades Tradicionais,

[...] a Cartografia Social - que vem se consolidando desde 2005 - passa a ser um instrumento de resgate e reforço de identidade e também uma força motriz para sua organização política e sustento de suas ações reivindicativas. A Cartografia Social, mais do que um produto cartográfico, é um processo protagonizado pelas próprias comunidades, visto que elas é que a realizam (op.cit, 2010, p.2). 
As comunidades remanescentes de quilombo têm em seu histórico repressão cultural e escravidão. Tornar sua cultura ativa num momento de aculturação foi senão um ato de coragem e manter hoje a relação de prática, como exemplos a alimentar e religiosa depois de longo processo de repressão carecem por vezes de fortalecimento em exercícios de autoconhecimento, principalmente pelos mais jovens.

Os resultados seguem nas análises de equilíbrio entre os objetos cartográficos e os sujeitos, no sentido amplo que resulta em uma contribuição de dimensão social e individual para cada membro desse processo. O território recebe essa parcela concentrada da cultura ancestral e mapeá-la coletivamente resguarda simbologias numa representação própria e singular, assim esse processo possibilitou uma discussão sobre o vínculo cultural dos sujeitos e sua terra criando um diálogo poderoso. Discussão essa, que nos leva a análise do mapa como instrumento para contextos conflituosos, mas também mostrou que as perspectivas transcendem a isso, enxergamos que é uma organização de identidade especial.

A Comunidade Quilombola da Serra do Evaristo (Figura 01), localizada no Município de Baturité, a 3 kms da sede e à 106 kms da capital cearense (Figura 02) teve uma parcela significativa na produção cartográfica, sendo esse o principal argumento para consistência ao fim do projeto. Com o fato de os agentes sociais serem protagonistas foi fundamental a participação, já que os próprios apontam como se organizam os elementos etnográficos no território. Nesse escopo metodológico analisa-se que a construção do mapa foi uma reunião de significados e a liberdade de ser auto-cartografia gerou o sentimento de autonomia. Os encontros deram-se nessa reunião para a elaboração técnica com legenda totalmente participativa, levando em consideração os elementos que seriam adicionados ou excluídos, na metodologia participativa observamos que o protagonismo contribui também na construção de outras temáticas cartográficas. 


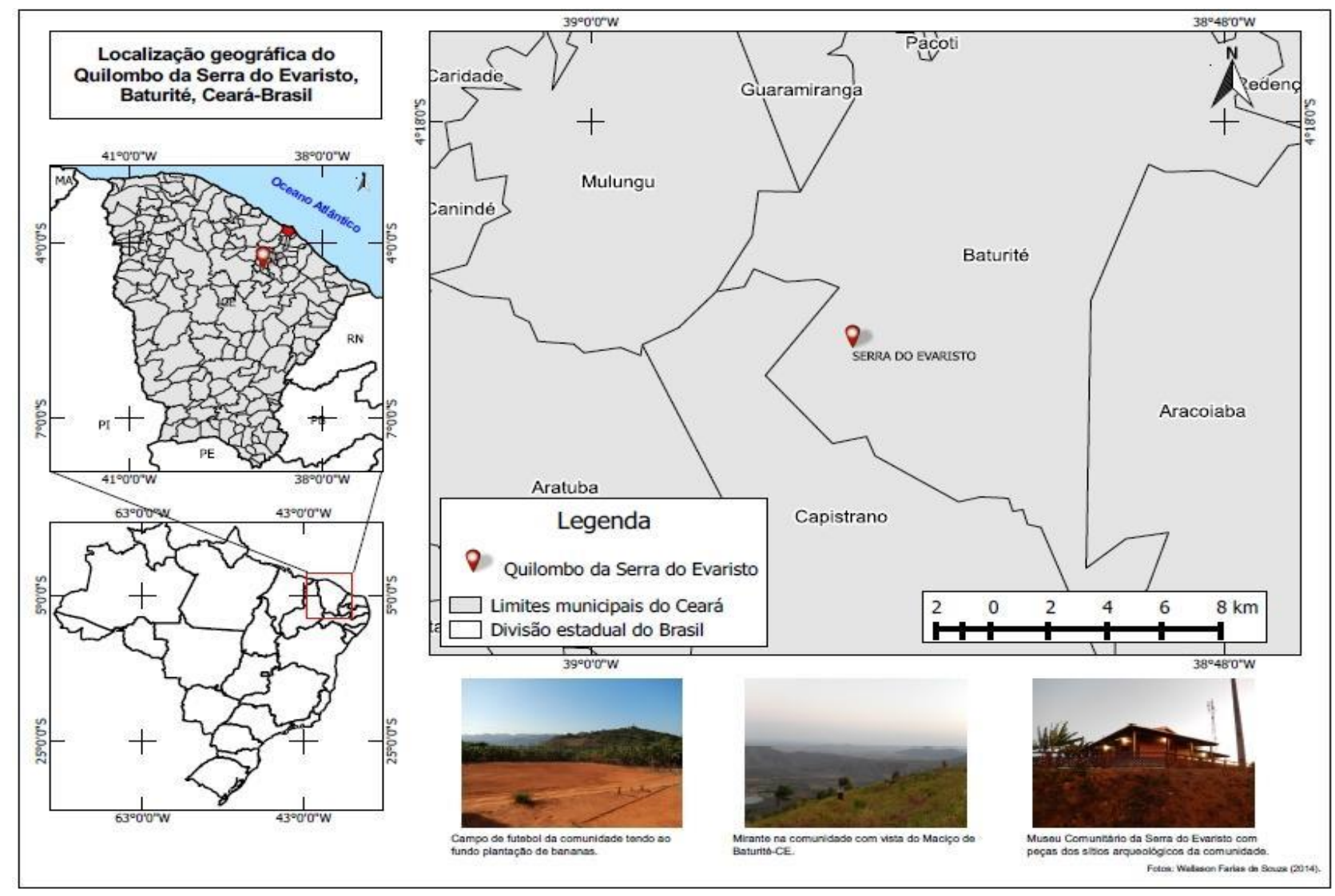

Figura 02 - Mapa de localização da comunidade quilombola Fonte: Laboratório de Cartografia (LABOCART- UFC) (2014)

Não demorou-se a concluir que é intrínseca na comunidade a relação dos sujeitos sociais e a espacialidade, embora seja um fato, uni-los no mapeamento torna útil diante de vulnerabilidades que não são incomuns. Observar o que significam as rotas e pontos afetivos tornou claro como culturalmente esse contexto do território faz a identidade individual e coletiva. As entrevistas semiestruturadas realizadas, refletiram que as principais lideranças apontaram elementos positivos em relação ao processo de mapeamento social, destacando que este possibilitou que a voz da comunidade fosse repercutida para ajudar a entender seus lugares presentes no território de maneira integrada.

A problemática maior a ser ressaltada foi escassez de água, embora seja o mais significativo e que mais afeta o coletivo, outros aspectos positivos merecem nossa atenção: com os achados de urnas funerárias foi implantado um museu pelo IPHAN, a medicina alternativa é parte da economia e isso os torna com enorme potencialidade turística. Talvez a maior das singularidades do quilombo seja sua divisão geográfica anteriormente citada, o território dividido pelos sobrenomes das famílias é também indicação de identidade e pertencimento (Figura 03). 


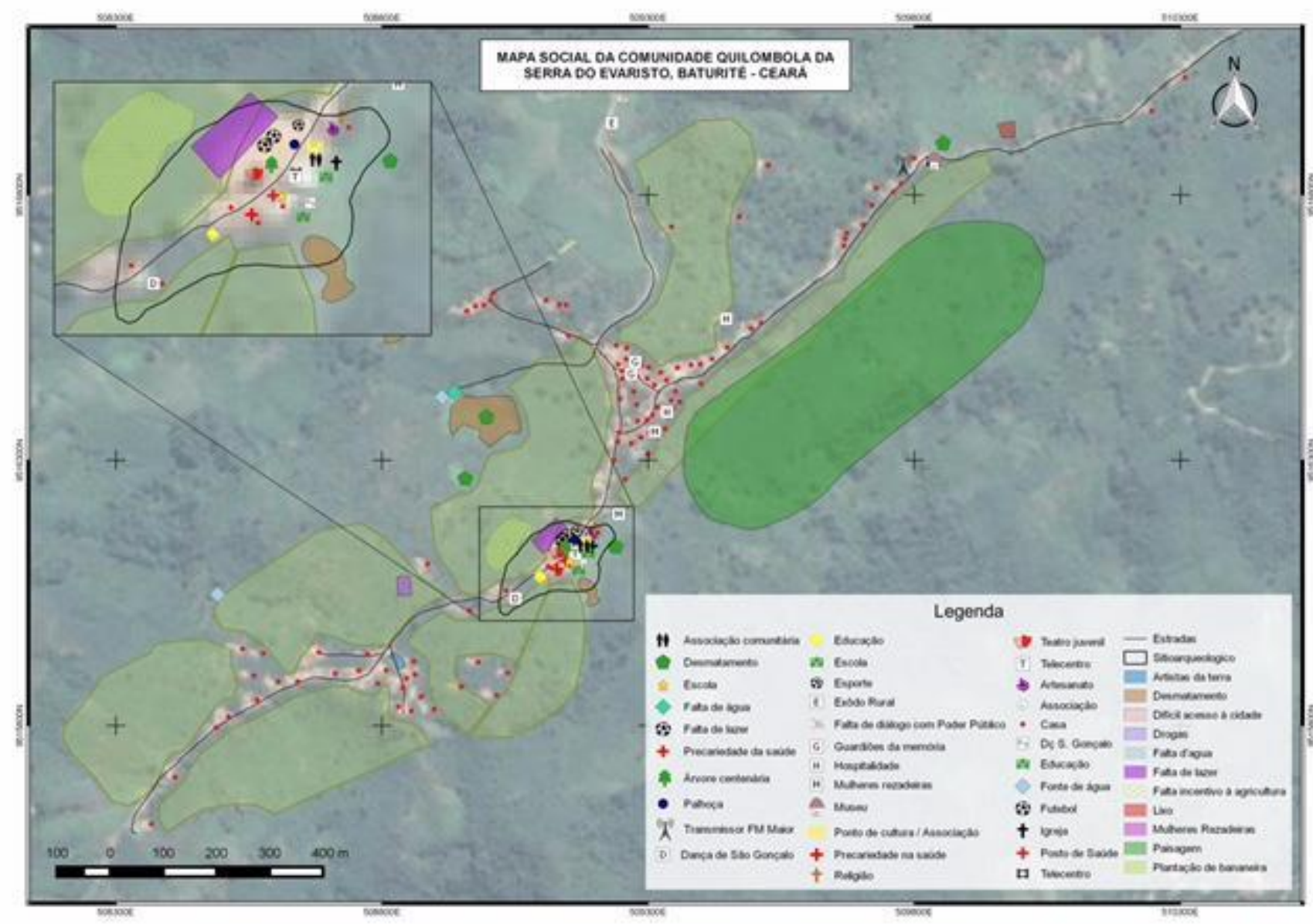

Figura 03: Cartografia Social Quilombo da Serra do Evaristo. Fonte: LABOCART/UFC

Na legenda: associação comunitária, área de desmatamento (espaço desmatado para construções e bananicultura). Escola (apenas ensino fundamental). Falta de água e lazer (espaço com problemas hídricos e com potencial para um possível equipamento de lazer). Precariedade na saúde (carência de um PSF). Árvore centenária (Árvore do Fato, onde se contam lendas da comunidade). Palhoça. Transmissor de rádio (antenas que emitem sinal de rádio). Dança de São Gonçalo (local de comemoração e festividade). Educação, escola, esporte. Êxodo rural (migração de habitantes da região). Guardiões da Memória (sujeitos sociais mais idosos que detém o conhecimento histórico da comunidade). Hospitalidade, mulheres rezadeiras (grupo religioso formado de mulheres). Museu (com os artefatos encontrados na comunidade). Ponto de cultura/associação (local para reuniões de moradores e comemorações). Religião, teatro juvenil, telecentro, artesanato, associação, casa, fonte de água, futebol, igreja, estradas, sítio arqueológico, artista da terra, difícil acesso à cidade, drogas, falta incentivo a agricultura, lixo, paisagem, plantação de bananeira. 
É interessante estabelecer uma reflexão, à luz de Gorayeb; Meireles (2014), sobre o fato da ocupação do território ser considerada como algo gerador de raízes e identidade, onde um grupo social não pode ser compreendido sem o seu território, no sentido de que a identidade sociocultural das pessoas está, invariavelmente, ligada aos atributos da paisagem.

Conforme os autores, sobre esse olhar, os territórios das comunidades tradicionais se caracterizam por serem, mais fortemente, ligados ao campo simbólico, e não simplesmente às relações de poder, propriedade ou controle político da hegemonia econômica circundante. Sendo importante observar que o sentimento de pertencimento à terra, à história, às lutas, à identidade, às práticas, às vivências, aos rituais, entre outros, se aglutinam formando uma conjuntura legitimadora dos territórios vividos, facilmente perceptível no momento da construção das legendas e do discurso que legitima as suas representações em sua maioria paisagens que refletem o que há de identidade dos sujeitos sociais.

\section{CONSIDERAÇÕES FINAIS}

Com o surgimento de diversas problemáticas oriundas das análises cartográficas, é possível projetar soluções para vendas de propriedades, cultivo de banana e o difícil acesso a comunidade para que desse modo sejam articuladas soluções em conjunto, todavia é notório perceber que além de dificuldades existem potencialidades que podem ajudar o desenvolvimento social interno e externo do quilombo, por exemplo: O turismo religioso, o turismo de saúde e a gastronomia com suas raízes ancestrais fazem parte de um potencial que rodeia a identidade coletiva do Evaristo. $\mathrm{O}$ Núcleo de Estudos Afro-brasileiros e Indígenas (NEABI) tem participado desse fortalecimento no que se refere ao autoconhecimento, através de atividades de extensão e pesquisa,

A comunidade visa uma melhoria de qualidade de vida a partir da educação, saúde, cultura e lazer. No desfecho da cartografia social os remanescentes de quilombo tiveram a oportunidade de reunir seus elementos positivos e negativos, sob o olhar da metodologia etnográfica pudemos estudar o caso pelo viés mais antropológico e analisar como esses fatores implicam na dinâmica da comunidade. A cartografia social, para o pesquisador, é a experiência de desprendimento, tendo em vista que o pertencimento concreto sobre o trabalho prático é do coletivo, porém, a interferência externa é o exercício pessoal em atividade de extensão.

Vale ressaltar, entretanto, que foi possível observar, na construção das das oficinas de Cartografia Social realizadas junto ao Quilombo da Serra do Evaristo, é sua marginalização, e a necessidade premente de serem debatidos os seus direitos junto ao poder público. 


\section{REFERÊNCIAS}

GORAYEB, Adryane. Cartografia Social e Populações Vulneráveis. In: Cartilha Rede de Mobilizadores - Oficina do Eixo Erradicação da Miséria, 2014. Disponível em http://www.mobilizadores.org.br/wp-content/uploads/2014/07/Cartilha-Cartografia-Social.pdf. Acesso em 12 de julho de 2016.

GORAYEB, Adryane; MEIRELES, Jeovah. Cartografia social vem se consolidando com instrumento de defesa de direitos. Rede Mobilizadores, 10 fev. 2014 Disponível em: <http://www.mobilizadores.org.br/coep/Publico/consultarConteudoGrupo.aspx?TP=V\&CO $\mathrm{DIGO}=\mathrm{C} 20142610482831>$.

LACOSTE, Yves. A geografia: isso serve, em primeiro lugar, para fazer a guerra. 4. ed. Campinas: Papirus, 1997.

LITTLER, Paul. E. (Org). Conhecimentos tradicionais para o Século XXI: etnografias da interficientificidade. Anablueme, São Paulo, 2010.

LAKATOS, Eva Maria, MARCONI, Maria de Andrade. Metodologia do trabalho científico. São Paulo, 1995.

OLIVEIRA, Marina Eduarda Armstrong de. et.all. O poder de resposta: a Cartografia Social dos Povos e Comunidades Tradicionais. In. Anais do ENG, 2010.

Recebido em: 14/08/2016

Aceito para publicação em: 01/10/2016 